\title{
Coyote Control: the Public Response
}

\section{LOUISE M. ARTHUR}

\begin{abstract}
A nationwide survey of public attitudes toward coyote control was conducted in 1976. Results from a set of questions addressing related wildlife issues revealed opposition to the killing of animals for food or for population control of predatory species. Forty-five percent also disapproved of legal game hunting. Only incident specific predator control was endorsed by most respondents. Twothirds of the respondents were aware of the coyote control issue or interested in it and were asked questions about coyote control in particular. Control killing of coyotes, even at risk to nontarget animals, received increasingly more approval as lamb losses were said to increase. However, given a choice of control methods, most respondents preferred the experimental, nonlethal methods. Of currently used lethal methods, fast acting poisons and shooting from the ground were judged more acceptable.
\end{abstract}

The decline of the sheep raising ind ustry in the Western United States has been attributed to a number of local and widespread problems, a major one being coyote (Canis latrans) predation of sheep and lambs (Gee et al. 1977; Pearson 1975). In spite of federal, state, and local programs to control coyotes, sheep ranchers continue to complain about high levels of lamb losses to coyote. Wildlife conservationists, on the other hand, argue that control efforts should be drastically limited, if not completely curtailed.

The problem is, in large part, a perceptual one. Whether or not ranchers are losing substantial proportions of their flocks to coyotes - and there is some controversy regarding the significance of these predation losses (Cain 1975; Tigner and Larson 1977; Wagner 1975) - they believe that coyotes are a major threat to the sheep-raising industry (Buys 1975; Gee et al. 1977). Whether or not coyotes are rural and urban pests and far from danger of extinction (Cain 1978), animal protectionists view them as part of our valuable wildlife resources and worthy of protection. Both sides of the issue have brought their concerns to the public arena, to a public already sensitized to environmental issues. Thus, control policy makers have become interested in understanding general public perceptions of control issues. They hope to be able to anticipate responses to policy changes in this increasingly controversial area. The USDA-U.S. Fish and Wildlife study described below was designed toward this objective.

\section{Survey Method and Results}

Data were collected in May-June 1976 from a random, selfweighting, stratified probability sample of telephone households in the 48 contiguous states and the District of Columbia. Within each household a respondent was randomly selected on the basis of sex and age (18 and older). Respondents in 2,041 households completed telephone interviews, resulting in a $78 \%$ response rate.

Approximately one-third of this sample had not heard of the rancher-environmentalist controversy over the killing of coyotes and had no interest in the issue, so were not required to answer questions specifically addressing the control issue. Instead, they answered only the survey items regarding more general wildlife issues, many of which related to the killing of animals. For

Author is agricultural economist, U.S. Dep. Agr., Economics, and Statistics Service, Oregeon State University, Corvallis.

This study was conducted by the USDA, Economics, Statistics, and Cooperatives Service and USDI Fish and Wildlife Service in cooperation with the University of Arizona, Tucson. I would like to thank R. Gum, E. Carpenter, and W. Shaw for their contributions to the design of the questionnaire.

Manuscript received March 5, 1979. instance, they were asked to rate how much an animal suffers as a result of the following practices: (1) "trapping wild animals with steel leghold traps, (2) killing instantly with guns, (3) using poisons that kill in less than a minute, (4) using poisons that kill in a few hours, (5) killing animals in meat packing plants, and (6) keeping animals in high quality zoos." All respondents rated these items on 0 to 10 scales, where a rating of 0 indicated that the practice caused no suffering at all and 10 indicated it caused "a lot of suffering." Mean responses are listed in Table 1. Trapping and slow acting poisons were judged to cause considerably more suffering than any other methods. Killing instantly with guns was rated as causing the least amount of suffering.

Table 1. Perceived amount of suffering caused by various methods of killing animals.

\begin{tabular}{lc}
\hline \hline Method & Mean points \\
\hline Trapping & 9.0 \\
Guns & 3.1 \\
Fast poisons & 5.0 \\
Slow poisons & 8.7 \\
Packing plants & 4.5 \\
Zoos & 4.2 \\
\hline
\end{tabular}

All respondents also answered questions concerning their attitudes toward the general concept of predator control and the killing of animals. When asked "if a wild animal kills a farmer's cows, sheep, or chickens on his property, do you think the farmer should have the right to kill that animal?", 73\% responded "yes." However, when asked "do you think the farmer should have the right to kill other animals of the same type to prevent future losses?", only $43 \%$ of those who answered affirmatively to the previous question agreed. Thus, control seems to be most acceptable if it is in direct response to a specific predation incident.

This apparent disapproval of predator population control may reflect a more general disapproval of the killing of any animal, for $45 \%$ of the respondents disapproved of legal game hunting and $61 \%$ responded that they did not like cattle, hogs, and sheep to be killed for food, even though many considered domestic animals an important source of protein. On the other hand, those who approved of game hunting and killing domestic animals for food were more likely to approve of incident-specific predator control, but were still no more likely to endorse gencral control of predatory species.

\section{Questions Directly Concerning Coyote Control}

The two-thirds of the sample which had heard of the rancherconservationist controversy over coyote control or were interested in it were asked a series of questions directly addressing control issues. First they were asked whether they were more concerned over the control killing of coyotes or the predatory killing of sheep by coyotes. Despite much greater affinities for sheep than coyotes noted earlier in the survey (see Stuby et al. 1979), there was about equal concern expressed for the killing of coyotes and sheep. However, as sheep and lamb losses to coyotes were hypothetically increased from $5 \%$ to $40 \%$ in four scenarios, respondents became more willing to condone the killing of coyotes, even at some risk to nontarget animals (Table 2). Again, it appears that people are more willing to support predator control efforts if they believe the predators are a direct cause of serious problems for ranchers.

If coyotes must be controlled, however, the public prefers some methods to others. Acceptability ratings for the various lethal and 
Table 2. Percent of survey respondents preferring various control strategies under four levels of lamb losses to coyotes.

\begin{tabular}{lcccc}
\hline Control strategy & $\begin{array}{c}5 \% \\
\text { Losses }\end{array}$ & $\begin{array}{c}10 \% \\
\text { Losses }\end{array}$ & $\begin{array}{c}20 \% \\
\text { Losses }\end{array}$ & $\begin{array}{c}40 \% \\
\text { Losses }\end{array}$ \\
\hline $\begin{array}{l}\text { Kill most coyotes, kill } \\
\text { some other animals }\end{array}$ & 16 & 28 & 47 & 61 \\
$\begin{array}{l}\text { Kill fewer coyotes, safe for } \\
\text { other animals }\end{array}$ & 71 & 66 & 50 & 37 \\
Kill no coyotes, sustain losses & 13 & 6 & 3 & 2 \\
\hline
\end{tabular}

nonlethal alternatives are listed in Table 3. Not surprisingly, the methods judged by all respondents to cause the most suffering trapping and slow poisons (Table 1)-were also judged the least acceptable, and the control methods judged to cause the least a mount of suffering - fast poisons and guns - were the most acceptable of the killing methods.

Table 3. Acceptability of coyote control alternatives.

\begin{tabular}{lc}
\hline \hline Alternative & Mean points $^{\mathrm{a}}$ \\
\hline Expcrimental nonlethal methods & \\
Repellant chemicals & 7.0 \\
Pay ranchers for losses & 3.2 \\
Guard dogs & 7.1 \\
Birth control & 5.8 \\
Pay ranchers not to raise sheep & 1.8 \\
Current lethal methods & \\
Fast poisons & 4.3 \\
Slow poisons & 1.3 \\
Aerial gunning & 2.5 \\
Denning & 2.3 \\
Ground shooting & 4.3 \\
Steel leghold traps & 1.6 \\
\hline
\end{tabular}

a-10 scale, indicating low to high acceptability.

General opposition to killing was reflected in that some experimental, nonlethal control methods were rated more acceptable than any of the currently used, lethal methods. These included repellent chemicals, guard dogs, and birth control. Rancher subsidies and indemnity payments, on the other hand, were less acceptable than some killing methods. These trends differed depending on whether respondents approved or disapproved of the killing of animals for predator control, food consumption, and game hunting. Those respondents who opposed control-even under conditions of high lamb losses-were more willing to institute rancher subsidies and indemnity payments and less likely to endorse use of guard dogs, chemicals, birth control, and lethal methods than other respondents.

Because even the more informed and/or concerned respondents were not expected to have knowledge of the specific impacts of each control alternative, these respondents were also asked to rate the relative importance of and tradeoffs among several general aspects of control killing by distributing 100 points among them (Metfessel 1949). The resulting mean point distribution is prescnted in Table 4.

Table 4. Relative importance of three aspects of coyote control methods.

\begin{tabular}{lc}
\hline \hline & Mean points \\
\hline Cost & 16 \\
Specificity $^{1}$ & 32 \\
Humaneness $^{2}$ & 57 \\
Total & 100 \\
\hline
\end{tabular}

I"That is, do they kill only coyotes that have killed sheep and lambs?"

2"That is, how little pain and suffering is caused the coyotes killed?"
Clearly, humaneness was the primary concern in the acceptability of a control method, perhaps explaining the high correlation between ratings of humaneness and acceptability of various methods (Tables 1 and 3 ). The second most important concern was for the specificity of the methods, which specificity in regard to accidental deaths of pets being judged most important ( 42 points of 100 ), other wild animals second ( 38 points), and nontarget coyotes least important ( 20 points).

\section{Conclusions}

That more than two-thirds of the respondents to this national survey had heard of or were interested in the controversy between sheep ranchers and environmentalists about coyote control was indeed surprising given the regionality and rural focus of the problem; although coyotes have been sighted in every state except Florida and Hawaii, most of the sheep and lamb predation occurs in the sheep producing regions of the Western United States. It was also interesting to note that the response of informed-interested respondents did not differ significantly from those who had not heard of the issue and were not concerned (Stuby et al. 1979).

Although most respondents expressed general disapproval of the killing of animals - whether by man or coyote-most people became willing to institute coyote control if unreasonable losses of lambs and sheep to coyotes are sustained. Certain nonlethal control methods were preferable to the methods currently in use, but the more humane lethal methods are acceptable under conditions of high lamb losses. Shooting coyotes from the ground and using fast-acting poisons were judged the most acceptable and most humane of currently available methods. Trapping with steel leghold traps and using slow acting poisons were judged the least acceptable of all lethal and nonlethal methods.

Use of toxicants to kill coyotes is currently limited by a Federal executive order (11643) baxning the interstate shipment and federal use of toxicants for predator control. Given this restriction and the impracticality of using ground shooting for widespread federal control-which presently accounts for an estimated $63 \%$ of the coyotes taken (Gum et al. 1978)-aerial gunning, using welltrained gunners who can kill coyotes instantly, becomes the most desirable of present alternatives from a social perspective. ${ }^{1}$ Nevertheless, these results indicate that efforts to develop nonlethal control methods and to obtain legal approval of the use of more recently developed predator-specific, fast acting poisons would elicit favorable public responses if the public were convinced of ranchers' needs for control.

"Interestingly, aerial gunning is also the most economically efficient of current legal alternatives (Gum et al. 1978)

\section{References}

Buys, C.L. 1975. Predator control and ranchers'attitudes. Environ. Behavior 7: 81-98.

Cain, S.A. 1975. Predator and pest control. Chapter 25. In H.P. Brokaw (ed.), Wildlife and America. 041-011-00043-2. U.S. Govt. Printing Office, Washington., D.C.

Gee, C.K., D.B. Nielsen, D.H. Stevens, and R.S. Magleby. 1977. Factors in the decline of sheep production in the Western United States. Agr. Econ. Rep. 377. U.S. Dep. Agr., Economic Res. Serv., Washington, D.C.

Gum, R.L., L.M. Arthur, and R.S. Magleby. 1978. Coyote control: A simulation evaluation of alternative strategies. Agr. Econ. Rep. 408. U.S. Dep. Agr., Economics, Statistics, Coop. Serv., Washington, D.C. 49 p.

Metfessel, M. 1947. A proposal for quantitative reporting of comparative judgments. J. Psychol. 29: 229-235.

Pearson, E.W. 1975. Sheep-raising in the 17 Western States: Populations, distributions, and trends. J. Range Manage. 28: 27-31.

Stuby, R., L.M. Arthur, and E.H. Carpenter. 1979. An analysis of public attitudes toward coyote control. Agr. Econ. Rep. U.S. Dep. Agr., Economics, Statistics, Coop. Serv. in press.

Tigner, J.R. and G.E. Larson. 1977. Sheep losses on selected ranchers in Wyoming. J. Range Manage. 39: 244-252.

Wagner, F.H. 1975. The predator control scene as of 1974. J. Range Manage. 28: 4-10. 